\title{
The Sentient, Skilled and Situated of Sustaining a Physical Activity Career: Pleasurable Interpretations of Corporeal Ambiguity
}

\begin{abstract}
In comparison to the natural sciences, there is a lack of empirically grounded social scientific research which addresses how people arrive at forming pleasurable interpretations of physical activity participation. Both social and natural conceptualisations of the bodily sensations evoked via physical activity involvement have also been restricted to pain and pleasure and pleasure-displeasure dualisms. Nevertheless, there is general agreement across these disciplines that pleasurable interpretations of physical activity participation encourage regular and sustained future involvement. We draw on carnal sociology to explain life history interview data from 30 varied physical activity careers to argue corporeal experiences of being physically active are more ambiguous than existing pleasure-pain dualisms suggest. Furthermore, interpreting these ambiguous corporeal senses as pleasurable was of central importance to sustaining a prolonged physical activity career, which we argue is a carnal skill that can be learned. This skill, possessed by those interviewees with the most prolonged physical activity careers, had been acquired through becoming accustomed to the unique situated sensual ambiguities of particular physical activities, as a type of existential connoisseurship. Future research might pay more attention to the ambiguity of physical activity involvement, the carnal interpretation of which carries important consequences for the likelihood of long-term participation.
\end{abstract}

Keywords: carnal sociology; physical activity; pleasure; corporeality; dualisms

Within the social sciences of sport and exercise, there is a relative lack of empirically grounded research which addresses how people arrive at forming pleasurable interpretations of physical activity participation. This is despite a more established evidence base in the natural sciences which argues that pleasurable interpretations of physical activity experiences are central to continued participation (Ekkekakis and Brand, 2019). A notable exception to this is recent work by Lev (2019), which explores the issue by explaining how becoming a long-distance runner involves learning to glean pleasure from the pain and bodily distress inherent to participation. Nettleton's (2013) ethnography of fell running, guided by carnal sociology, also makes some important links between pleasure and continued participation, whilst presenting evidence which suggests that experiences of doing physical activity are more complex than the pain-pleasure dualism assumed by Lev (2019). A reductive and dualistic pleasure-displeasure conceptualisation of the corporeal sensations triggered by physical activity involvement is also popular within the natural sciences.

Drawing on interview data from 30 varied physical activity careers and utilising carnal sociology, this paper argues that corporeal experiences of being physically active are more ambiguous than existing pleasure-pain dualisms suggest and interpreting these ambiguous corporeal senses as pleasurable is of central importance to sustaining a 
prolonged physical activity career, which is a carnal skill that can be learned. As our research brings greater nuance to a fundamental difference as to why some people sustain regular physical activity participation while others do not, the findings are of central relevance to physical activity policies and research agendas which continue to stress the health benefits of regular lifelong participation (Department of Health and Social Care, 2019; World Health Organization (WHO), 2010). Especially as we offer insight into how pleasurable interpretations are formed and less favourable appraisals might be reinterpreted. Physical activity is defined 'as any bodily movement produced by skeletal muscles that results in energy expenditure' (Caspersen, 1985: 126), and in this paper we focus on the forms of physical activity people choose to intentionally engage with during their leisure time.

\section{Literature Review}

Within the natural sciences, there is a well-established evidence base suggesting the relative physiological intensity of physical activity participation is a central element in the psychological interpretation of whether an individual appraises the experience as being characterised by pleasure or displeasure (Ekkekakis, 2003; Ekkekakis et al., 2005; Frazão et al., 2016). These findings, drawn predominantly from laboratorybased studies, have been connected with biological reward mechanisms (Esch and Stefano, 2010) and theories of affect grounded in evolutionary psychology (Ekkekakis, 2003) to theorise that pleasant responses are associated with increased motivation for continued participation. While some authors writing from this position claim this connection is strong enough to be incorporated into exercise prescriptions and physical activity recommendations to maximise pleasurable responses and increase the chances of maintained participation (Ekkekakis and Brand, 2019), other natural scientists are less convinced about the practical efficacy of their findings. Rose and Parfitt (2010) and Frazão et al. (2016) have expressed concern that away from the controlled laboratory environment of supervised physical activity bouts, the everyday contexts in which physical activity takes place are more complex and contain various additional external cues likely to influence focus and the interpretation of physiological sensations. Moreover, evidence of this type is also grounded in evolutionary dualistic understandings of human responses to physical activity participation (see Ekkekakis et al., 2011). In addition to reducing research participants' interpretations of the physical activity sensations experienced to a single point on a pleasure-displeasure scale, the dual-mode theory underpinning most of this experimental research proposes that affective responses to physical activity are determined by the constant interplay between cognitive parameters and physiological cues (Ekkekakis et al., 2011). Therefore, mind and body are treated as inter-related, but separate and distinguishable entities, investigated in settings removed from the practical everyday contexts in which physical activity participation occurs.

Within the social sciences of physical activity there is greater appreciation of the influence of context upon pleasure, although there have been considerably fewer studies that focus on pleasure per se. Furthermore, the interpretive mechanisms 
underpinning how pleasurable appraisals of being physically active are established have been less directly explored in comparison to the natural sciences. Phoenix and Orr (2014) have proposed types of pleasure that can be experienced through physical activity participation, namely sensual pleasure, documented pleasure, the pleasure of habitual action, and the pleasure of immersion. While Wellard (2012) has devised the framework of body-reflexive pleasures to draw attention to the significant role played by the process of reflecting upon the social, physiological and psychological of prior experiences in contemplating how physical activity might be pleasurable. It is only recent work by Lev (2019), which draws on Becker's (1973) study of marihuana users, that directly and empirically addresses how pleasurable physical activity conceptions are formed in the case becoming a long-distance runner, by learning to derive pleasure during episodes of pain. However, this falls into the dualistic assumption of understanding pleasure as no more than an enjoyable oppositional interpretation to that of unwelcome pain, whilst overlooking the dimension of ambiguity also described by Becker (1973). Thus, as in the natural sciences, there is evidence that the social sciences also trap pleasurable interpretations of physical activity involvement within a dualistic and dichotomous configuration. An exception is Zeiler's (2010) phenomenological analysis of bodily pleasure instigated via physical activity. While this study gets at some of the ambiguities of the lived body using Leder's (1990) conception of eu-appearance, it is restricted by Leder's belief that pleasurable sensations are not immediately experienced within the body (Zeiler, 2010).

Elsewhere, other qualitative research makes reference to pleasurable experiences and interpretations attached to the particular bodily sensations stimulated by yoga (Humberstone and Stuart, 2016), boxing and running (Allen-Collinson and Owton, 2015), walking and mountain biking (Brown, 2017), fell running (Nettleton, 2013), and bodybuilding (Shilling and Bunsell, 2009). The rich and detailed ethnography of fell running provided by Nettleton (2013: 209) is revealing in this regard, which crafts the concept of existential capital to explain how the 'magic, memories, skills, frailties, dangers, pain and fun associated with the embodied practice of fell running' accrue over time as a fleshy reality that only other fell runners who have immersed themselves in such experiences can legitimately appreciate. Although the runners felt as though no words could do justice to the uniquely personal corporeal aliveness experienced, the mutual passion of fell running functioned as a shared subcultural pleasure. While not an explicit interrogation of how pleasurable interpretations were formed amongst the fell runners, this account depicts a sophisticated insight into how pleasurable interpretations are shaped from ambiguous and sometimes unsettling corporeal sensations. As Nettleton's paper illustrates, pleasurable interpretations have behavioural consequences in terms of seeking further involvement and conducive to an active identity, an argument also shared amongst natural and social scientists of physical activity (Ekkekakis and Brand, 2019; Ekkekakis et al., 2011; Phoenix and Orr, 2014; Wellard, 2012).

Accordingly, within the social sciences there is a need to investigate how pleasurable conceptions of physical activity involvement are formed from ambiguous experiences, in a way that advances the understanding of pleasure beyond dualistic constraints. To 
do this, we follow Nettleton (2013) by drawing upon the possibilities of carnal sociology to explain data from a qualitative study interested in why people become involved in, drop-out of and re-engage with being physically active.

\section{Corporeal Ambiguity, Pleasurable Interpretations and Carnal Sociology}

Nettleton locates existential capital within carnal sociology, an approach concerned with placing greater focus on 'what the body does' than the tendency within the sociology of the body to pay attention to 'what is done to the body' (Crossley, 1995: 43). Following some disagreement as to whether Merleau-Ponty's $(1962 ; 1988)$ notion of body-subject adds a necessary dimension to Bourdieu's (1984) habitus to realise a fleshier and more sentient understanding of human ways of being-in-the-world (see Crossley, 1995; 2001; Howson and Inglis, 2001), Nettleton (2013) illustrates that carnal sociology, as put forward by Crossley through drawing on the body-subject, provides for a fuller understanding of embodiment. In particular, with the intention to get at what the body does, carnal sociology does away with the Cartesian ontology that mind and body are distinctly separate entities, common to the way much sociology has been written (Crossley, 1995; Wacquant, 2011). This innovation provides the opportunity to produce rich forms of practical knowledge, especially relevant to ordinary and everyday experience (Wacquant, 2011). Although, carnal sociology is not confined to debunking only those social analyses framed by unjustifiably reductive mind-body dualisms (Crossley, 1995). Indeed, as well as dismissing the long-held assumption that the 'active mind' is mounted on a 'dumb body', the carnal also rejects conventional dualistic understandings that social structures are solely external constraints imposed upon human agents and that knowledge is an exclusively mental configuration of accumulated representations and information chunks (Wacquant, 2015: 2).

Through a carnal perspective the social world is understood from the 'bottom-up' and humans, as social agents, simultaneously act within and upon it (Wacquant, 2015: 3). Subsequently, the body is always understood in the context of the social formation in which it is situated (Crossley, 2001; de Rond et al., 2019; Wacquant, 2015). Wacquant (2015: 3), a key proponent of carnal sociology, points out that humans are not solely neo-Kantian symbolic animals, but also 'sentient, suffering, skilled, sedimented, and situated'. Without overlooking that these properties of the carnal are aspects of the same whole, for the purposes of our argument concerning the translation of corporeal ambiguity into pleasurable interpretations, we are particularly interested in the sentient, skilled, and situated, which Wacquant (2015: 3-4) outlines as follows,

Sentient: the agent is not only endowed with senses, exteroceptive, proprioceptive, and interoceptive; she also makes sense of what her sensorium captures... Skilled: the social agent can "make a difference" because, through experience and training, she acquires capacities to act and the dexterity to do things competently... Situated: we are both protected by and locked in the fragile physical envelope of our mortal 
organism, which cannot be at two places at a given time but integrates the traces of the many places we have occupied over time.

The sentient therefore acknowledges the possibility that physiologically defined types and intensities of physical activity do not simply do things to a passive body and produce pre-programmed natural responses. Instead, the carnal body is alive and able to make sense of the sensual and, as the data we present highlights, people can make markedly contrasting interpretations of the same carnal responses to physical activity. Attached to this is the potential for interpretations of ambiguous corporeal sensations to be learned as a skill, such as making sense of the ambiguous corporeality of physical activity in a pleasurable fashion. Previous work by de Rond et al. (2019), as well as Becker's (1973) study, also infer that sensemaking is a skilled act. Paramount to making sense of the world through the lived body are the social circumstances and physical environments in which we find ourselves situated when making such interpretations. Although the influence of situatedness does not impact upon our interpretations each time afresh, as we also bring into every situated interpretation of sensemaking our prior experiences via already embodied ways of being. As, simultaneously, physical activity-specific corporealities structure particular ways of subcultural and existential being (Nettleton, 2013). In terms of the structuring of physical activity sensations, it is crucial to pick-up on Leder's (1990) observation of the increasingly disembodied sedentary context of Western societies, where the body has been left to congeal. Any corporeal sense of aliveness is thus inseparable from the general absence of the body within everyday experience, meaning intentional physical activity participation represents a sudden lived departure from absent to intense embodiment. Acknowledging this both delineates a shared aspect of the situatedness in which our participants described and interpreted their experiences of physical activity involvement and goes some way to rebuffing the chief criticism of a carnal sociology of the body, that it overlooks the structural conditions of the everyday social world in which the carnal is acted upon (Howson and Inglis, 2001).

An agenda has also been laid out to get a better grasp of the physically active self by explicitly engaging with carnal sociology (Hockey and Allen-Collinson, 2007). Prior neglect of what the body does within the sociology of sport and exercise is difficult to explain given the strong emphasis within the natural sciences on the wellbeing of physical activity participation and efforts to encourage sedentary bodies to become more active. Public issues in which a carnal sociology is potentially well-placed to generate insightful policy implications grounded in lived experience. We utilise carnal sociology in this paper to add nuance to the dualistic pleasure-pain conceptualisation of physical activity sensations by devoting our attention to the significance of pleasurable interpretations of corporeal ambiguities in sustaining a physical activity career, which, we argue, is carnal skill that can be acquired.

\section{Methods}

As part of wider study interested in why people become involved in, drop-out of and re-engage with being physically active across the life course, data analysed in this 
paper is informed by life history methodologies (Atkinson, 1998; Plummer, 2001; Thomas and Znaniecki, 1918). Concerned with gaining insights into and potential explanations of the key moments, stages, phases, transitions and cycles that shape a life, Plummer's (2001) work in this area was particularly influential and guided the collection and analysis of life history interviews with 30 participants. To promote a perspective grounded in different types of case (Hammersley, 2011), and in the interests of achieving some form of analytic generalisability (Katz, 2004; 2015), accounts were sought from people with a variety of physical activity experiences in terms of type and amount. An experience-based sampling strategy of maximal variety according to physical activity involvement was therefore employed. In the first instance, those with physically active identities were recruited from a triathlon club and a gym in South East England and those who did not perceive themselves to possess such an identity were recruited though the lead author's personal connections across the South East and West Midlands of England. Snowball sampling then increased the number of participants from both groups and was also used to gather a third group of interviewees who used terms such as 'casual', 'spontaneous' and 'inconsistent' to describe their physical activity participation. This produced a participant sample whose experiences of physical activity ranged from minimal involvement since attending compulsory physical education classes around 40 years earlier, to a current international level masters athlete who had been regularly active for the majority of the past 70 years. Physical activities interviewees had engaged with included badminton, yoga, walking, soccer, gymnastics, rugby, hockey, running, triathlon, swimming, cycling, horse riding, skateboarding, basketball, dancing, netball, ballet, skiing, martial arts, weightlifting, hiking, climbing, caving, mountain biking, tennis and cricket. Recruitment variety was also achieved in terms of gender and age, with the final sample comprising 15 men and 15 women, ranging from 22 to 75 years of age.

Interviews navigated the extent and type of participant's physical activity involvement using a career approach. This is a position derived from pioneering life history studies of identities, values, attitudes, behaviours and 'the problem of social happiness' (Shaw, 1930; Thomas and Znaniecki, 1918: 84), fundamental to the establishment of Chicago School research methods (Becker et al., 1961; Plummer, 2001). While these previous career investigations demanded recruiting participants with particular and unconventional experiences such as immigration (Thomas and Znaniecki, 1918), marihuana use (Becker, 1973), medical school training (Becker et al., 1961), and being categorised as a juvenile delinquent (Shaw, 1930), physical activity experiences are arguably better suited to a career approach as most people will possess some form of prior experience. A career framework emphasises how prior experiences are vital to making choices and developing perspectives that structure our conceptualisations of the world (Becker et al., 1961). Though we recognise that the actual events of interviewee's recollected experiences cannot simply be captured, interpretations and reinterpretations of recollected experiences that participants choose to tell, whether fact or fiction, are just as powerful in shaping one's future identities, interactions and behaviours (Plummer, 2001; Sartre, 1963). Interviews were of a semi-structured format and employed 'grand-tours' of each physical activity career, before entering into 'mini-tours' of each type of physical activity participated in (Plummer, 2001: 145), 
focusing on reasons for initially becoming involved, maintaining and ceasing involvement, and re-engagement. 24 hours and 53 minutes of interview data were collected, with single interviews ranging from 25 minutes to 1 hour 37 minutes in duration. Interviews were conducted, audio-recorded and transcribed verbatim by the lead author. A proportionate ethical review of the study was approved in conjunction with the research governance procedures of the relevant university. In the interests of anonymity, pseudonyms are used to present the data provided by interviewees.

Widely referred to as an exemplar of rigour in qualitative analysis (Flick, 2007; Seale, 1999), data were analysed using the detailed comparative logic of analytic induction (Al) (Znaniecki, 1934), where each physical activity career was exhaustively scrutinised and compared case-by-case to build-up a generalised working hypothesis that was tested and revised where necessary in the process of examining every case (Katz, 2015). Al is useful at revealing how interpretations, conceptualisations and perspectives of the phenomena under investigation develop, persist and change over time, thus encouraging analytic generalisations to be made through applying the essential features from one case to the context of further cases (Katz, 2015; Plummer, 2001; Znaniecki, 1934). To do this, the lead author read each transcript, identifying 'logical classes of data' that referred to descriptions and interpretations of physical activity experiences and instances of starting, re-engaging with, or ceasing physical activity participation (Znaniecki, 1934: 259). Each transcript was then revisited to make analytic comparisons and connections between and within each case, concerning changes in type and regularity of physical activity participation and the reasons identified by participants for these changes. This revealed a connection between pleasure and sustained physical activity involvement. The nature of this pattern was then scrutinised further to develop a working hypothesis of how and from where participants derived the type of pleasurable interpretations that motivated prolonged physical activity involvement by re-reading each transcript in full to better understand the context in which these interpretations took place. During the final stage of analysis, at instances where the pattern of pleasure and sustained involvement was apparent, data essential to this connection were extracted from each transcript, compared and crafted into an overall working hypothesis (Plummer, 2001; Znaniecki, 1934). This analysis revealed the significance of the embodied sensations of physical activity involvement, such as 'sweating', 'feeling the buzz' and a 'pounding heart' to the interpretations of participants, which led us in the direction of carnal sociology to explain the findings.

Through undertaking $\mathrm{Al}$, sporting achievements and providing a sense of freedom from uncertain and stressful periods of life were also identified as ways in which physical activity participation contributed to pleasure. Nonetheless, it was the pleasurable interpretation of the body's response to the ambiguous corporeal sensations of physical activity involvement that acted as the most enduring factor in sustaining a physical activity career. 


\section{Findings and Discussion}

The findings presented in this section show that those who had formed pleasurable conceptions of physical activity involvement also had the most extensive physical activity careers. In contrast, interviewees who expressed little to no recollection of deriving pleasure from their physical activity involvement reported notably brief physical activity careers and did not consider themselves regularly active at the time of interview. It is this pattern in the data which is the focus of the analysis and discussion. Guided by carnal sociology, we argue corporeal experiences of being physically active are more ambiguous than existing pleasure-pain dualisms suggest, interpreting these ambiguous corporeal senses as pleasurable is of central importance to sustaining a prolonged physical activity career, and such interpretations are a carnal skill that can be learned.

\section{The Corporeal Ambiguity of Physical Activity Involvement}

Like the majority of participants who referred to more intense types of physical activity participation, Harry recollected how the experience whilst involved is unsettling, ambiguous and sometimes imbued with conflict, yet followed by a largely pleasurable interpretation afterwards,

I've had those two voices on my shoulder... 'why ya' doin' this? just stop, you don't need to run anymore', and the other one's goin' 'come on! What ya doin'? Keep runnin', keep goin"... get through it... and at the end of it, ya' go 'that was really good... l've pushed me-self there'.

The notion of pushing oneself to the extent of experiencing pain, retrospectively appraised as favourable, was more explicitly articulated by Charlotte, 'I guess it hurts, most of the time, but in a good way... as in the pain of running'. Although not as explicitly masochistic as the physical activity careers of participants such as Harry and Charlotte, interviewees primarily involved in less competitive physical activities produced comparable experiences of bodily responses such as sweating, yet interpreted this bodily response in contrasting ways,

Something like going in the gym, is not for everybody, those that do it, fine, they enjoy it, great, but it's not for everyone, just standing in a gym and sweating... I just did not enjoy sweating and working hard... to go, be in a gym and sweat, no, that doesn't inspire me at all. (Helen)

I feel like l'm going crazy, like I love it!... getting really hot and sweaty, and when I kind of start to feel the sweat going into my eyes, I'm like 'yeah, I've worked really hard, I'm happy now' (laughs). (Yasmin)

Beth, who possessed a relatively sporadic career of inconsistent physical activity involvement, had come to interpret sweating as a necessity for the post-participation interpretation of pleasure. 
Goin' to the gym and sweating loads... you'd think you wouldn't feel clean afterwards, but... after you've had a shower and stuff you just feel, like you've sweated out everything that's bad and you feel good about yourself, you feel happy.

It is recognised that physical activity participation gives rise to experiencing a 'gut feeling', indicative of pleasure or displeasure, but not necessarily attached to either (Conroy and Berry, 2017: 232). The data collected in the current study suggests these feelings, too sophisticated to correspond with a narrow bi-directional continuum of pleasure/displeasure, are also more complex than attempting to distinguish between the descriptions attached to enjoyable pleasure and unwelcome pain offered in the social sciences. For such purposes, the work of Allen-Collinson and Owton (2015) is important in getting at embodied background feelings of the pleasure of doing physical activity, where it is contended that intense feelings of pain are only a moment away from falling into bodily consciousness. Our data suggests this blurring between pain and pleasure is so frequent and inherent to the described experiences of physical activity, that it represents a dimension of sensuous physical activity experience on its own grounds, in the form of corporeal ambiguity. As such, intentional physical activity can be understood as one of the body's more aggressive actions when contextualised within the situatedness of being-in-the-world (Crossley, 1995; Merleau-Ponty, 1962). Indeed, the apparent need to develop a 'feel for' (Crossley, 2001: 323) the intense sentience of physical activity involvement to maintain participation is unsurprising when understood within the sedentary epoch in which the contemporary body is situated (Leder, 1990). The obscure nature of encountering the ambiguous blurring between pleasure and pain and sentient bodily shifts between physical activity involvement and the 'reality' of sedentariness was richly detailed by Chris, when discussing his experiences of lifting weights at the gym,

Ya just focusin' on, on getting ya heart beatin'... making your muscles sore... it's just a nice feelin', I can't really describe it... I suppose in a way it's almost like being on drugs... when you do a really heavy set... you beat your personal best and put the weight down and then all the blood rushes out... rushes into the muscle and you... feel your heart like screaming at ya... it's just such a buzz. Nothing else kind of matters at the time... it just gradually whittles down again, and you come back to reality (laughs).

As also highlighted by Chris, differentiations made by participants between bodily sensations when doing an activity and interpretations of their embodiment following the activity, were paramount to revealing how retrospective pleasurable interpretations of physical activity involvement depended upon the appraisal of the body's response to being active. As Zeiler (2010) has observed, certain variants of bodily pleasure hinge upon a reflective bodily self-awareness, and participants who welcomed the ambiguity of these intense embodied sensations had sought further involvement to experience similar situations of specific activities, such as weightlifting and running, to develop some sense of familiarity with certain types of ambiguous embodiment. Like Nettleton's (2013) fell runners, they had become connoisseurs of their own involvement, and revelled in experiences so ambiguous they found them problematic 
to convey in words. For others with noticeably less extensive physical activity careers, ambiguous sensations instigated by performing comparable activities in similar environments, albeit to lesser extremes, were appraised as unfavourable and thus avoided, with any fleeting re-engagement with physical activity justified on the grounds of health, not pleasure,

I lost a stone and a half when my son was gettin' married... I was going to the gym every morning before work... and I was on milkshake drinks, to lose it, and just having the one meal a day and I couldn't have kept that up forever, so of course once I started eating normally and not going to the gym, 'cos I didn't enjoy the gym, I hated it... when these people say 'oh, it's like a buzz', I never ever got that (laughs). (Helen)

\section{Sustaining a Physical Activity Career: Skilled Connoisseurship of Interpreting Corporeal Ambiguity as Pleasurable}

Interviewees who had a feel for interpreting the ambiguity of their heightened corporeal awareness as pleasurable did so in regard to specific physical activities they had become accustomed to practicing, through establishing a stabilised belongingness to situated ways of being and doing in the world (Merleau-Ponty, 1988). This holds some common ground with what Phoenix and Orr (2014) have termed the pleasure of habitual action, where repetitive physical activity engagement not only induces bodily responses that captivate the consciousness during participation, but also alters the way the body feels in a more enduring fashion. Grant provided an example of this,

After the run you just feel like really good about yourself, you feel really tired, but it's like a good kinda tired... even if you've like pulled muscles... I don't know if it's the adrenaline... or what it is, but you do feel better.

These enduring changes to how the body senses and interprets the world around it, while also existing as a forever situated object from which one cannot be removed (Crossley, 1995; de Rond et al., 2019; Nettleton, 2013), provide insight into the relational stories people tell themselves to validate pleasurable interpretations of the ambiguous corporeal experience of being physically active. Accordingly, such stories focus on connections that hinge upon the situated materiality of the physical world and the situated motions of the body (Brown, 2017; Hitchings and Latham, 2017), which can only be assembled and understood through doing (Nettleton, 2013). Paige, a skilled connoisseur of assimilating existential aspects of the ambiguous embodiment of her triathlon training into pleasurable interpretations, explained this in some depth,

People say 'oh, you enjoy running', and I think 'do I?!', I don't know!! Because there's sometimes you're out and you think 'this is awful', you know 'why am I doing this?', it's freezing cold or it's raining ... you get that... early stage of just being out of breath, and then you get into that... fluidity, and there are some days that you feel you could run all day, and then there's other days where your limbs just seem to bang against each other 
and they don't flow, and you just think 'God, what do I look like?'... you just feel like you're an elephant running up the road.

Across participants' storied experiences of physical activity involvement, it was apparent that those who made the most ecstatic interpretations of their experiences were those who had engaged in, and frequently sought, the most ambiguous and potentially unsettling forms of bodily engagement. Yasmin's interpretations and motivations highlight this,

[I] Get a real kind of adrenaline buzz off sprinting up the hills, erm, and just kind of generally pushing my body to, the max... I do feel like it can become a bit of an addiction... I suppose it's the hormones that's released when you're... pushing yourself... to those kind of extremes.

Although, this ambiguity was not always characterised by physiological notions of exercise intensity attached to increases in heart rate and metabolism beyond a certain threshold, instead it was broader sense of interpretive carnal aliveness that was desired and reflectively welcomed (Zeiler, 2010). Julian, a veteran international hockey player, competitive runner and duathlete in his seventies, chose to refer to gardening as an activity that induced some of the most intense bodily sensations both during and following his involvement,

Gardening's the worst thing... you use muscles you never use and you always ache... you're bending over... so ya, ya back's hurting, ya pulling ya Achilles... you go in [to the house], you think 'Oh god!'.. I was in agony... and now I just ache, so it's quite nice (laughs).

Mike, an experienced gym user, was conscious of how becoming a regular gym goer took a period of learning about the unfamiliar bodily sensations produced and then retrospectively interpreting these as favourable,

It's uncomfortable, definitely, you come in the gym for the first day, you're muscles are aching... you've gotta fight through that... you don't become good at something if you don't put the time in, it's like any trade... and that gymnasium is, you... working on your body, and you'll get that reward through... mobility, health... a clearer mind... the endorphin release and that, there's a lot of benefits but someone just coming in through the door won't see those.

The body's endorphin response was heavily cited by regularly active participants as a post-participation feature that appeared to assist in developing a perspective characterised by pleasure. Although, it was gaining a degree of familiarity over the sentient and situated embodied ambiguity unique to specific physical activities which served the purpose of cementing regularly active participants' interpretations as pleasurable. Brown's (2017) ethnographic study of walkers and mountain bikers underlines the significant bearing pleasurable appraisals of sensations arising from contact with ground surface textures have upon the desire to sustain participation. For the mountain bikers, 'sensations of tipping, dizziness, spinning, turning, undulating, reeling, and swaying' were viewed as pleasurable because they offered a form of 
unique but generally familiar corporeal experience memorably different from routine everyday feelings (Brown, 2017: 311). In the present study, Kevin explained the unsettling bodily process he had become accustomed to during long-distance running races, articulated in a storied format using subcultural jargon to convey the acquaintance he had formed with the dynamic stinging sensation in his legs:

You give yourself some stingers, and they always hurt, and then you find if you're going up you've gotta come down and sometimes they're worse than going up... and then you come towards the end whereby you might decide it's time to give yourself a really good push before doing your warming down, and so you go for burn... and then you settle down.

Activity-specific bodily scripts, such as Kevin's, gave regularly active interviewees some form of familiarity with the type of embodied experiences they had become well practiced at gaining pleasure from through a sentient appreciation that unfolds from the body (de Rond et al., 2019; Nettleton, 2013). Nevertheless, stories drawn from the same activity by different participants also carried firm sentiments of personal agency. Evan went as far as suggesting consistent encounters with a heightened sense of corporeal aliveness from Ironman training accumulated into a personal distinction that created a distance between himself and family members,

It's almost as if they're another breed... I had some tensions with my parents over it in the past... one of them was when I was training for Ironman... they were concerned that I was overdoing it... that is a concern for people who don't do regular sport... l've come back from a run absolutely sweating... I've really pushed myself and it's been great... even though I look a wreck, I feel great, and they say 'why the hell do you do that to yourself... why are you killing yourself that way?!', I said 'well I'm not, I'm ok, I'm fine, give me 10 minutes'... they could never imagine doing that... l've spoken to Louise, my sister... psychologically she doesn't have the same instinct... she's never really wanted to exercise, she's done $5 \mathrm{ks}$ and stuff... I remember her finishing her first race, saying 'why the hell do you do that?! It's too painful'.

\section{The Carnal Skill of Interpreting Physical Activity Sensations as Pleasurable}

There was also evidence that some participants who described their physical activity habits as spontaneous and casual were in the process of learning that they preferred the corporeal sensations of some activities over others, but this depended upon the environment in which the body was situated (Wacquant, 2015). Billy had arrived at the realisation that he could retrospectively derive pleasure from going beyond the uncomfortable pain of a gym-based circuits class, in contrast to his prior experiences of cross county running while at school,

I hated cross country with an absolute passion... that was like a punishment more than anything... I just didn't enjoy it... it was always cold and miserable, wet, running along in like a field (laughs)... it was just terrible, I 
just hated it... I prefer running on a treadmill than I do outside... on a treadmill I feel more in control... it's a lot easier than running on the road... I've started doin' circuit training... it's only half an hour long, and I hate the whole half an hour, but once it's done, I'm like 'I'm glad I did that', because I don't enjoy the discomfort... it's just uncomfortable and painful, you're just sweating. l've always been quite lazy, like physically and just in general, so when I'm in discomfort I stop... obviously to progress you need to push through... you need to get through that pain barrier... I've started to realise, as l've got older and matured a bit.

Specifically, Billy had 'matured' through exposure to the situated corporeal sentience of practicing different physical activities in contrasting physical environments and, consequently, making reflective interpretations. Although, as Wacquant (2015: 5) points out, the practical schemata of the 'cognitive, conative and affective' that shape human interpretations are not fixed but always in the making as we act within and upon the world. In this vein, Graham, 25 years old than Billy, also recalled an 'absolute hatred' for the 'punishment' of doing cross country at school,

The teachers who were there... late seventies, early eighties perceived it as if we were like a minor public school, so cross country was 'good for the soul'... we went out in the snow.

Yet, at the time of interview around 30 years later, Graham had reinterpreted the carnal sensations of cross country as being perversely pleasurable and, along with swimming, had become a preferred form of physical activity,

I can remember the first time I did cross country, and just feeling physically sick, it was just horrible, which is bizarre... because for the past seven years l've been doing cross country with a triathlon club. There's a perverse enjoyment to that, it's hard, its off-season, it's cold, it's muddy... you get up early on a Sunday morning and it's freezing... you know ya guna get yourself muddy.

A reason Graham offered for the interpretive shift in making more pleasurable sense of the embodied sensations of cross country was that it represents a corporeal divergence away from being situated in the sedentariness of adulthood, especially within the context of his existing occupation,

Physical activity plays an important role in the wellbeing agenda at work... rather than sitting there stewing... it just works the tension away. Sometimes the worst thing you feel like you could do is put your body under extra pressure, but I think sometimes that's the best thing you can do... you're releasing endorphins, which make you feel better. It's nice to clear some thinking space... living in the moment, switching off.

Central to Graham's reinterpretation of the senses of cross country, are schemas which originate from the sedentary position his body regularly occupies in contemporary society (Leder, 1990), an embodiment he takes with him into the corporeal field of cross country. It would therefore appear that making sense of the 
extreme sensual intensities of particular physical activities is as much about the embodiment that one enters the field with as it is the distinct corporeal sentience of specific activities (Wacquant, 2015). Graham's account of reinterpreting the ambiguous and initially unwelcome corporeality of cross country participation as pleasurable raises the issue that understanding pleasurable interpretations of physical activity demands paying considerable attention to existing biographical structures and are more fluid, changeable and complex than the fixed reductive pleasure-displeasure dualisms proposed in the natural sciences. Instead, interpreting physical activity sensations as pleasurable requires a process of reflection informed by one's ongoing carnal situatedness of being in and making sense of the world (Crossley, 1995; Merleau-Ponty, 1988; Wacquant, 2015) and does not simply start and stop as prompted by physiological parameters indicative of the physically active body (see Ekkekakis et al., 2011).

As theorised elsewhere, pleasure is neither a constant feature of the corporeal sensations experienced when doing physical activity, nor restricted to the time at which involvement occurs (Phoenix and Orr, 2014; Zeiler, 2010). Hence, the skill of carnally interpreting physical activity involvement as pleasurable lies in a willingness to becoming familiar with the corporeal ambiguity evoked by the harsh and sudden contrast between the intense physically active body and the mundane sedentariness of contemporary Western societies. A skill that can only be realised once sufficient existential experience of this lived contrast has been accrued (Nettleton, 2013), by carnally diverging from the grain of the mundane (Merleau-Ponty, 1988).

\section{Conclusion}

By utilising carnal sociology and drawing upon qualitative life history data from 30 varied physical activity careers, this paper has proposed corporeal experiences of being physically active are more ambiguous than existing pleasure-pain dualisms suggest. Furthermore, interpreting these ambiguous corporeal senses as pleasurable is of central importance to sustaining a prolonged physical activity career, which is a carnal skill that can be learned. The findings also indicate that pleasure is not inherent to the experience or an automatic outcome of physical activity involvement. In this regard, the carnal situatedness of both the sensed environment that physical activity involvement takes place and the broader society in which the body finds itself need to be considered. Although a carnal perspective can throw-up alternative ways of being in the world, such ways of being are often difficult for one to maintain on a long-term basis. In the case of becoming more physically active in a regular fashion, this change must take place within the present historical moment where the body has become more sedentary, and in some form will have already structured ways of being in the world for each social agent. At the same time, the very premise that the body has been left to congeal in many everyday scenarios is arguably what makes the divergent sensations of doing physical activity an attractive and pleasurable regular pastime for those who participate. 
However, many physical activities are not equally accessible to or valued by different social classes (Nettleton, 2013). This is a limitation of the study on which our analysis is based, as social class was not factored into the variety of the sample, which should be considered in future investigations, as the appetite to acquire and maintain a healthy body is more prevalent amongst the identities of people in positions of greater social advantage (Bourdieu, 1984). Alongside pleasure and pain, future sociological research would be well-informed to pay further attention to the corporeal ambiguities of physical activity and fully recognise the policy implications. While current agendas to increase physical activity participation levels are based around the appeal of the health-related benefits of what physical activity can do to the body (WHO, 2010), our fleshy analysis of varied physical activity careers indicates that interpretations of bodily responses are always shaped by pre-existing ways of being that people enter the situated contexts of participation with. Importantly, these sentient interpretations of intensely ambiguous carnal responses to being physically active carried significant qualitative weight in the desire to learn to enjoy and sustain longterm participation in an existential and heuristic fashion, whereas the attraction of prospective health benefits were rarely mentioned by participants. Along these lines, future research might focus exclusively on how pleasurable interpretations have carnally developed amongst those previously averse to regular physical activity participation. Our analysis might also inspire natural scientists to conduct more fieldbased research by examining pleasure with greater sensitivity to how it plays out within naturally occurring contexts using approaches that are not confined to mind-body and pleasure-displeasure dualisms.

\section{References}

Allen-Collinson $\mathrm{J}$ and Owton $\mathrm{H}$ (2015) Intense embodiment: Senses of heat in women's running and boxing. Body \& Society 21(2): 245-268.

Atkinson R (1998) The Life Story Interview. London: Sage.

Becker H (1973) Outsiders: Studies in the Sociology of Deviance. New York: The Free Press.

Becker H, Geer B, Hughes E, et al. (1961) Boys in White: Student Culture in Medical School. London: Transaction Publishers.

Bourdieu P (1984) Distinction: A Social Critique of the Judgement of Taste. London: Routledge Kegan \& Paul.

Brown K (2017) The haptic pleasures of ground-feel: The role of textured terrain in motivating regular exercise. Health \& Place 46: 307-314. 
Caspersen C, Powell K and Christenson G (1985) Physical activity, exercise, and physical fitness: Definitions and distinctions for health-related research. Public Health Reports 100(2): 126.

Conroy D and Berry T (2017) Automatic affective evaluations of physical activity. Exercise and Sport Sciences Reviews 45(4): 230-237.

Crossley N (1995) Merleau-Ponty, the elusive body and carnal sociology. Body \& Society 1(1): 43-63.

Crossley N (2001) Embodiment and social structure: A response to Howson and Inglis. The Sociological Review 49(3): 318-326.

de Rond M, Holeman I and Howard-Grenville J (2019) Sensemaking from the body: An enactive ethnography of rowing the Amazon. Academy of Management Journal 62(6): 1961-1988.

Department of Health and Social Care (2019) UK Chief Medical Officers' Physical Activity Guidelines. London: Crown Copyright.

Ekkekakis $P$ (2003) Pleasure and displeasure from the body: Perspectives from exercise. Cognition and Emotion 17(2): 213-239.

Ekkekakis $P$ and Brand R (2019) Affective responses to and automatic affective valuations of physical activity: Fifty years of progress on the seminal question in exercise psychology. Psychology of Sport and Exercise 42: 130-137.

Ekkekakis P, Hall E and Petruzzello S (2005) Variation and homogeneity in affective responses to physical activity of varying intensities: An alternative perspective on dose-response based on evolutionary considerations. Journal of Sports Sciences 23(5): 477-500.

Ekkekakis P, Parfitt G and Petruzzello S (2011) The pleasure and displeasure people feel when they exercise at different intensities. Sports Medicine 41(8): 641-671.

Esch T and Stefano G (2010) Endogenous reward mechanisms and their importance in stress reduction, exercise and the brain. Archives of Medical Science 6(3): 447. 
Flick U (2007) Managing Quality in Qualitative Research. London: Sage.

Frazão D, de Farias Junior L, Dantas T, et al. (2016) Feeling of pleasure to highintensity interval exercise is dependent of the number of work bouts and physical activity status. PLOS ONE 11(3).

Hammersley M (2011) On Becker's studies of marijuana use as an example of analytic induction. Philosophy of the Social Sciences 41: 535-566.

Hitchings R and Latham A (2017) Exercise and environment: New qualitative work to link popular practice and public health. Health \& Place 46: 300-306.

Hockey $\mathrm{J}$ and Allen-Collinson $\mathrm{J}$ (2007) Grasping the phenomenology of sporting bodies. International Review for the Sociology of Sport 42(2): 115-131.

Howson A and Inglis D (2001) The body in sociology: Tensions inside and outside sociological thought. The Sociological Review 49(3): 297-317.

Humberstone B and Stuart S (2016) Older women, exercise to music, and yoga: Senses of pleasure? Journal of Aging and Physical Activity 24: 412-418.

Katz J (2004) On the rhetoric and politics of ethnographic methodology. The Annals of the American Academy of Political and Social Science 595: 280-308.

Katz J (2015) Situational evidence: Strategies for causal reasoning from observational field notes. Sociological Methods \& Research 44: 108-144.

Leder D (1990) The Absent Body. Chicago: University of Chicago Press.

Lev A (2019) Becoming a long-distance runner - Deriving pleasure and contentment in times of pain and bodily distress. Leisure Studies 38(6): 790-803.

Merleau-Ponty M (1962) Phenomenology of Perception. London: Routledge Kegan \& Paul.

Merleau-Ponty M (1988) In Praise of Philosophy and other Essays. Evanston: Northwestern University Press.

Nettleton S (2013) Cementing relations within a sporting field: Fell running in the English Lake District and the acquisition of existential capital. Cultural Sociology 7(2): 196-210. 
Phoenix C and Orr N (2014) Pleasure: A forgotten dimension of physical activity in older age. Social Science \& Medicine 115: 94-102.

Plummer K (2001) Documents of Life 2: An Invitation to a Critical Humanism. London: Sage.

Rose E and Parfitt G (2010) Pleasant for some and unpleasant for others: A protocol analysis of the cognitive factors that influence affective responses to exercise. International Journal of Behavioral Nutrition and Physical Activity 7(15).

Sartre JP (1963) Search for a Method. New York: Vintage Books.

Seale C (1999) The Quality of Qualitative Research. London: Sage.

Shaw C (1930) The Jack-Roller: A Delinquent Boy's own Story. Chicago: University of Chicago Press.

Shilling C and Bunsell T (2009) The female bodybuilder as a gender outlaw. Qualitative Research in Sport and Exercise 1(2): 141-159.

Thomas W and Znaniecki F (1918) The Polish Peasant in Europe and America: Monograph of an Immigrant Group (Vol. 1). Boston: The Gorham Press.

Wacquant L (2011) Habitus as topic and tool: Reflections on becoming a prizefighter. Qualitative Research in Psychology 8(1): 81-92.

Wacquant L (2015) For a sociology of flesh and blood. Qualitative Sociology 38: 1-11. Wellard I (2012) Body-reflexive pleasures: Exploring bodily experiences within the context of sport and physical activity. Sport, Education and Society 17(1): 2133.

World Health Organization (2010) Global Recommendations on Physical Activity for Health. Geneva: World Health Organization.

Zeiler K (2010) A phenomenological analysis of bodily self-awareness in the experience of pain and pleasure: On dys-appearance and euappearance. Medicine, Health Care and Philosophy 13(4), 333-342.

Znaniecki F (1934) The Method of Sociology. New York: Rinehart \& Company. 